\title{
BMJ Open Relationship between high-sensitivity C reactive protein and the risk of gallstone disease: results from the Kailuan cohort study
}

\author{
Tong Liu, ${ }^{1}$ Sarah Tan Siyin, ${ }^{2}$ Nan Yao, ${ }^{1}$ Ning Duan, ${ }^{1}$ Guoshuai Xu, ${ }^{1}$ Wenqiang Li, ${ }^{1}$ \\ Jun Qu (D) , ${ }^{1}$ Siqing Liu ${ }^{3}$
}

To cite: Liu T, Siyin ST, Yao N, et al. Relationship between high-sensitivity $\mathrm{C}$ reactive protein and the risk of gallstone disease: results from the Kailuan cohort study. BMJ Open 2020;10:e035880. doi:10.1136/ bmjopen-2019-035880

- Prepublication history and additional material for this paper is available online. To view these files, please visit the journal online (http://dx.doi.org/10. 1136/bmjopen-2019-035880).

JQ and SL contributed equally.

TL and STS are joint first authors.

Received 23 November 2019 Revised 30 July 2020 Accepted 14 August 2020

Check for updates

(c) Author(s) (or their employer(s)) 2020. Re-use permitted under CC BY-NC. No commercial re-use. See rights and permissions. Published by BMJ.

${ }^{1}$ Department of General Surgery, Aerospace Central Hospital,

Beijing, China

${ }^{2}$ Department of General Surgery, Beijing Children's Hospital,

National Center for Children's Health, Beijing, China ${ }^{3}$ Department of Hepatological Surgery, Kailuan General Hospital, Tangshan, China

Correspondence to

Professor Jun Qu;

qujunchief@163.com

\section{ABSTRACT}

Objectives Gallstone disease (GSD) can be caused by various health and clinical factors such as obesity, dyslipidaemia and an unhealthy diet, all of which are associated with higher high-sensitivity $C$ reactive protein (hs-CRP) concentrations. Whether hs-CRP represents an independent risk factor for GSD is still unclear. We prospectively investigated hs-CRP in relation to the occurrence of GSD based on the Kailuan study.

Study design Prospective cohort study.

Setting The Kailuan cohort study was conducted in Tangshan City in northern China.

Participants 95319 participants who were free from GSD were recruited in this study. Epidemiological data, anthropometric parameters and biochemical data of participants were collected.

Primary and secondary outcome measures Cox proportional hazards regression models were used to evaluate the association between hs-CRP concentrations and the risk of GSD after adjustments for potential confounders.

Results During the mean 7.58 years of follow-up among 95319 participants, 4205 participants were identified as newly diagnosed with GSD or having undergone cholecystectomy for cholelithiasis. Compared with the hs-CRP $<1 \mathrm{mg} / \mathrm{L}$ group, elevated hs-CRP concentrations were significantly associated with higher risk of GSD with the corresponding HR of 1.11 (95\% Cl 1.03 to 1.19), 1.12 (95\% Cl 1.04 to 1.22$)$ in the $1 \leq \mathrm{hs}-\mathrm{CRP} \leq 3 \mathrm{mg} / \mathrm{L}$ and hs$\mathrm{CRP}>3 \mathrm{mg} / \mathrm{L}$ group, respectively. The multivariate model which included hs-CRP not only had a better line of fitness but also had better predictive values to help identify new cases of GSD during follow-up.

Conclusion Elevated hs-CRP concentration is an independent risk factor for new-onset GSD among the Chinese population.

Trial registration number ChiCTR-TNC-11001489.

\section{INTRODUCTION}

Gallstone disease (GSD) is the most common disease of the biliary tract and the leading cause of gastrointestinal-related inpatient admissions. ${ }^{1}$ The prevalence and incidence of GSD appear to be higher in developed countries than in developing countries like
Strengths and limitations of this study

- Ultrasound examination was used in this study and was able to represent the true incidence of gallstone disease (GSD) in a defined population.

- This study is a large-scale population-based study, with a high number of new-onset GSD cases.

- Distinguishment between the two different types of stones (cholesterol and pigment) could not be carried out via ultrasonographic examination.

- GSD incidence was higher in women, but no data concerning the number of pregnancies or the frequency of oral contraceptives were used in our study.

China. $^{2-4}$ The third National Health and Nutrition Examination Survey estimated 20 million adults (6.3million men and 14.2 million women) in the USA are afflicted with GSD, with the cost of treatment estimated at 6.2 billion annually. ${ }^{56}$ GSD increases the incidence of all-cause mortality as well as cancer and cardiovascular-related mortality. ${ }^{78}$ The pain caused by GSD in the right upper quadrant can seriously impact quality of life. Previous cohort studies have demonstrated that gallstones found in the general population can cause symptomatic disease in $18 \%-24 \%$ of patients. In addition, $3 \%-8 \%$ of patients suffer from complications like acute cholecystitis, gallstone ileus, pancreatitis, gallbladder empyema or perforation, causing GSD to be a major public health problem. ${ }^{9-12}$

Several risk factors for GSD are well established, including ageing, female gender, ethnicity/genetics, pregnancy, family history of GSD and sedentary lifestyle. ${ }^{13-16}$ Previous studies have illustrated that inflammation is closely related with cardiovascular disease, atherosclerosis and hypertension. $\mathrm{C}$ reactive protein (CRP) is generally measured in inflammation as a non-specific acute-phase 
protein. CRP and high-sensitivity $\mathrm{C}$ reactive protein (hsCRP) are essentially the same, with the main difference between them being analytical sensitivities and assay ranges. ${ }^{17-19}$ Besides the aforementioned chronic diseases, elevated hs-CRP has been proven to be linked to various health metrics and clinical factors such as obesity, dyslipidaemia, unhealthy diet, diabetes and lack of physical activity, ${ }^{20-24}$ all of which may predispose the individual to GSD. Whether elevated hs-CRP concentration represents an independent risk factor for GSD after traditional risk factors are taken into account is still unclear. We therefore conducted this study to prospectively explore potential associations of hs-CRP with new-onset GSD based on the Kailuan cohort study.

\section{MATERIALS AND METHODS}

\section{Patient and public involvement}

Patients and the public were not involved in the development, design or analysis of this study.

\section{Kailuan study}

The data were obtained from health examinations of employees of the Kailuan Company in Tangshan city, which is situated $150 \mathrm{~km}$ southeast of Beijing. The Kailuan Company covers a wide range of industries and fields, including coal products, machine building, electric power, chemical production, transportation, construction and healthcare. The Kailuan study, a prospective population-based study, was designed to investigate risk factors for chronic diseases. From July 2006 to October 2007, all 155418 employees (including retired employees) of the Kailuan Company were invited to participate. A total of 101510 participants $(65.3 \%)$ agreed, and written informed consent was obtained. These participants underwent complimentary routine medical examinations every 2 years. All examination reports were reported to participants after 1 week.

\section{Study population}

A total of 101510 working and retired employees from the Kailuan Corporation underwent the baseline examination from July 2006 to October 2007 at Kailuan General Hospital and its 10 affiliated hospitals. Information including physical examination, type-B ultrasound examination, blood sample, urine sample and biochemical tests was collected. Questionnaires were done via face-to-face interviews by the medical staff and trained research nurses. Participants were given repeated questionnaires and underwent medical examinations biennially. In the current study, we excluded 4974 participants with a history of GSD (4737 stones cases, 237 cholecystectomy cases), 757 with data missing from type-B ultrasound examination, 954 participants without measurement of hs-CRP and a final 860 participants without data of Body Mass Index (BMI, in $\mathrm{kg} / \mathrm{m}^{2}$ ), total cholesterol (TC, in $\mathrm{mmol} / \mathrm{L}$ ), triglyceride (TG, in $\mathrm{mmol} / \mathrm{L}$ ), fasting blood glucose (FBG, in $\mathrm{mmol} / \mathrm{L}$ ), systolic blood pressure (SBP,

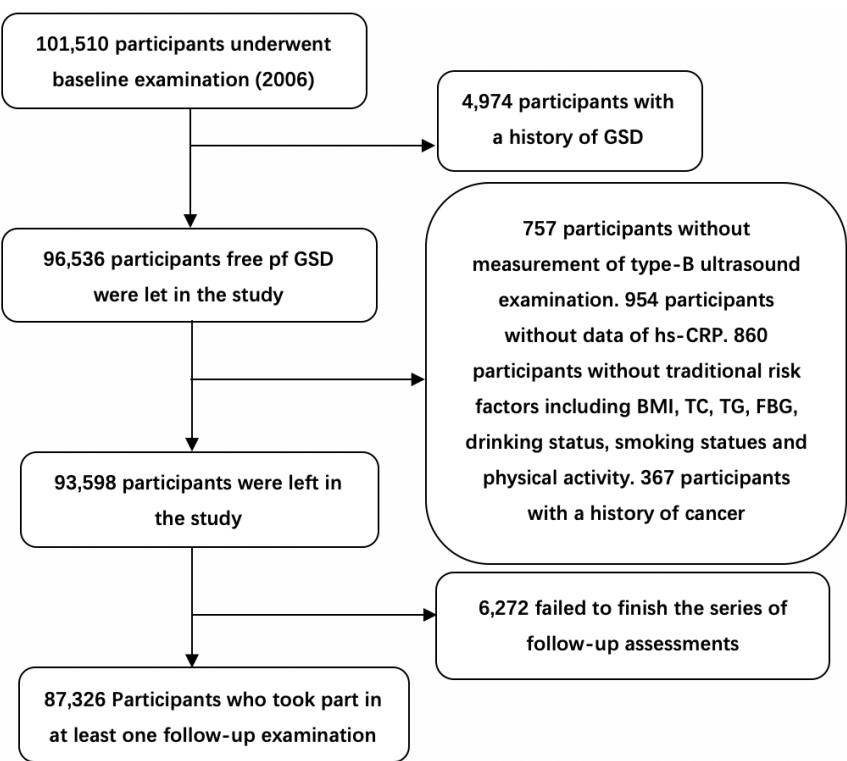

Figure 1 Procedure of participant screening. BMI, Body Mass Index; FBG, fasting blood glucose; GSD, gallstone disease; hs-CRP, high-sensitivity $C$ reactive protein; TC, total cholesterol; TG, triglyceride.

in $\mathrm{mm} \mathrm{Hg}$ ) and diastolic blood pressure (DBP, in $\mathrm{mm}$ $\mathrm{Hg}$ ), alcohol and tobacco consumption, and exercise frequency. Due to environmental metabolic disorders in patients with malignant tumours, we also excluded 367 participants with a history of cancer. Subsequent biennial follow-up examinations were conducted until the endpoint of this study (31 December 2015). A total of 6272 participants failed to complete the series of assessments. A total of 87326 participants who participated in at least one follow-up examination were ultimately recruited in this study. Participant screening details are shown in figure 1.

\section{Epidemiological survey and anthropometric parameters}

All patients underwent an interview with a standardised questionnaire which included questions on smoking status, level of physical activity and drinking intake. Anthropomorphic parameters including height, weight and waist circumference (WC) were measured. ${ }^{25} 26$ The BMI was calculated as the ratio of body weight (kilogram) divided by the square of body height (metre). A minimum of a 5 min rest, three readings of SBP and DBP were taken by using a mercury sphygmomanometer with a cuff of appropriate size. The average of three readings was used for the analysis. Hypertension was defined as the presence of any of the following: $\mathrm{SBP} \geq 140 \mathrm{~mm} \mathrm{Hg}$ and/or $\mathrm{DBP} \geq 90 \mathrm{~mm} \mathrm{Hg}$, a history of hypertension or the usage of antihypertensive treatment. Smoking status was defined as having at least one cigarette every day in the recent year. Drinking status was defined as having taken $100 \mathrm{~mL} /$ day (alcohol contents $>50 \%$ ) of alcohol on average for more than 1 year, and physical exercise as exercising $\geq 3$ times/week, $\geq 30 \mathrm{~min} /$ time. $^{2728}$ 
Determination of plasma hs-CRP levels and other biochemical indicators

Overnight fasting (at least 8 hours) blood samples were collected from the cubital vein at 07:00-21:00 on the physical examination day and transfused into vacuum tubes containing EDTA. TG and TC were both measured using the enzymatic method. FBG was measured using the hexokinase/glucose-6-phosphate dehydrogenase method. Plasma hs-CRP was measured using a commercial, high-sensitivity particle-enhanced immunonephelometry assay (Cias Latex CRP-H, Kanto Chemical Co., Tokyo, Japan) with a detection limit of $0.1 \mathrm{mg} / \mathrm{L}$. In accordance with the guidelines from the Centers for Disease Control and Prevention and the American Heart Association, participants were categorised into three groups based on their hs-CRP concentration: hs-CRP $<1 \mathrm{mg} / \mathrm{L}, 1 \mathrm{mg} /$ $\mathrm{L} \leq \mathrm{hs}-\mathrm{CRP} \leq 3 \mathrm{mg} / \mathrm{L}$ and hs-CRP $>3 \mathrm{mg} / \mathrm{L} .{ }^{29}$ All the plasma samples were analysed using an autoanalyzer (Hitachi 747; Hitachi, Tokyo, Japan) at Kailuan General Hospital central laboratory. Diabetes was defined according to the criteria of the American Diabetes Association: FBG $7.0 \mathrm{mmol} / \mathrm{L}$ and/or a self-reported history of diagnosis, and/or previous or current hypoglycaemic therapy.

\section{Determination of GSD}

The presence of GSD at the baseline examination and new-onset GSD cases during all follow-up examinations were assessed by ultrasound examination. PHILIPS HD-15 colour Doppler ultrasound scanner with a probe frequency of $3.5 \mathrm{MHz}$ was used to diagnose GSD cases. After at least 8 hours of fasting, ultrasound examination was performed in the abdominal region (examination of liver, gallbladder, pancreas and spleen in supine position). Cases of GSD excluded gallbladder polyps and included only presence of gallbladder stones and history of cholecystectomy, which were based on the presence of 'movable hyperechoic foci with acoustic shadow' and whether gallbladder removal due to cholelithiasis had occurred.

\section{Statistical analysis}

Data input was carried out by trained nurses of each participating hospital and transferred to the Oracle $10 \mathrm{~g}$ database located in Kailuan Hospital. Continuous and normally distributed variables were presented as means $\pm \mathrm{SD}$ and compared using one-way analysis of variance. Data in the skewed distribution were described by median $\pm \mathrm{IQR}$ and analysed using non-parametric tests. Categorical variables were presented as $\mathrm{n}(\%)$ and compared using $\chi^{2}$ test. Logarithmic transformation was used to incorporate hs-CRP for analyses with continuous variables to diminish the effect of extreme observations. Person-years of follow-up were calculated as the ending point of the first examination until the diagnosis of new-onset GSD or censoring, or end of follow-ups, or GSD unrelated death, whichever occurred first. We used Cox proportional hazard model to calculate HRs and 95\% CIs for new-onset GSD by using $\log$ (hs-CRP) in the regression model as a continuous variable. Several multivariable Cox proportional hazard models were adjusted for the effects of confounding covariates. Similar analytical methods were used to test the effects of the three hs-CRP groups on the risk of GSD. To identify the association between hs-CRP and new-onset GSD, subgroup analyses were carried out by stratifying participants according to sex, age (in years) (youth: $\leq 45$, middle age: $45-59$ and old age: $\geq 60$ ) or BMI (in $\mathrm{kg} / \mathrm{m}^{2}$ ) (normal: <24, overweight: 24 28, obese: $\geq 28$ ). Akaike information criterion (AIC) was used as a measure of the goodness of fit of the multivariate models. The discriminatory capability of the two multivariate models was evaluated using c statistics. In the sensitivity analysis, 3515 participants with hs-CRP $>10 \mathrm{mg} / \mathrm{L}$ were further excluded to eliminate the effect of acute inflammatory response. Reported $p$ values were two-sided, and $p<0.05$ was recorded as significantly different. All statistical analyses were performed using SAS V.9.4 statistical software.

\section{RESULTS}

The mean age was $50.78 \pm 12.01$ years old with 75141 (78.83\%) men and 20178 (21.17\%) women. The baseline characteristics for participants stratified by hs-CRP levels are shown in table 1. Participants with higher hs-CRP concentrations were older, had larger $\mathrm{WC}$, and higher SBP, DBP, TC, FBG and white blood cell count. Elevated hs-CRP concentration groups were associated with higher prevalence of hypertension and diabetes, and lower prevalence of drinking status, smoking and exercising. It is interesting to note that of the three groups, the concentrations of TG, TC, alanine aminotransferase (ALT) and the prevalence of drinking status, smoking status and physical activity were the highest in participants with hs-CRP of $1-3 \mathrm{mg} / \mathrm{L}$.

The follow-up period ended on 31 December 2015, with a median of 7.59 years for 87326 participants. A total of 4205 participants were newly diagnosed with GSD or had underwent cholecystectomy for cholelithiasis. It is worth noting that 3460 participants died before the end of follow-up or the occurrence of GSD. These participants were also included as they were involved in at least one follow-up examination. Table 2 shows the crude and adjusted HRs of new-onset GSD for per unit of $\log$ (hs-CRP). The HR for the association between $\log$ (hs-CRP) and GSD was 1.14 (95\% CI 1.12 to 1.17 ) in the univariate model, 1.06 (95\% CI 1.04 to 1.08 ) after adjusting for age and sex, and 1.03 (95\% CI 1.01 to 1.05 ) after adjustment for sex, age, TC, TG, BMI, TC, TG, ALT, smoking, drinking status, diabetes, hypertension and physical activity.

Table 3 displays the incidence of GSD and the association of the three prespecified hs-CRP groups with GSD. The crude incidence of GSD per 1000 person-years was 7.10 (7.55 in women, 6.96 in men). The age-standardised and sex-standardised overall incidence of GSD in this study was 6.99 per 1000 person-years. Our study indicated a clear trend based on hs-CRP concentrations, 
Table 1 Baseline characteristics of the participants stratified by hs-CRP subgroups

\begin{tabular}{|c|c|c|c|c|c|c|}
\hline & \multicolumn{6}{|l|}{ hs-CRP } \\
\hline & Total & $<1 \mathrm{mg} / \mathrm{L}$ & $1-3 \mathrm{mg} / \mathrm{L}$ & $>3 \mathrm{mg} / \mathrm{L}$ & $F / X^{2}$ & $P$ value \\
\hline Number & 87326 & 48552 & 22086 & 16688 & & \\
\hline Male, n (\%) & $75141(78.83)$ & $40788(79.64)$ & $19496(78.77)$ & $14857(76.77)$ & 61.48 & $<0.001$ \\
\hline $\mathrm{TG}$ (mmol/L) & 1.27 (0.90 1.94) & $1.21(0.85 \sim 1.81)$ & $1.39(0.98 \sim 2.1)$ & 1.35 (0.94 2.06) & 912.97 & $<0.001$ \\
\hline $\mathrm{SBP}(\mathrm{mm} \mathrm{Hg})$ & $130.40 \pm 20.67$ & $128.46 \pm 19.88$ & $132.39 \pm 21.06$ & $133.44 \pm 21.75$ & 500.76 & $<0.001$ \\
\hline $\mathrm{DBP}(\mathrm{mm} \mathrm{Hg})$ & $83.44 \pm 11.69$ & $82.71 \pm 11.46$ & $84.38 \pm 11.80$ & $84.43 \pm 12.03$ & 214.62 & $<0.001$ \\
\hline WC $(\mathrm{cm})$ & $86.92 \pm 9.95$ & $85.19 \pm 9.52$ & $88.38 \pm 9.68$ & $90.01 \pm 10.44$ & 1845.37 & $<0.001$ \\
\hline BMI $\left(\mathrm{kg} / \mathrm{m}^{2}\right)$ & $25.09 \pm 3.47$ & $24.56 \pm 3.29$ & $25.80 \pm 3.45$ & $25.66 \pm 3.71$ & 1294.93 & $<0.001$ \\
\hline Diabetes, n (\%) & $8305(8.71)$ & $3437(6.71)$ & $2596(10.49)$ & $2272(11.74)$ & 527.49 & $<0.001$ \\
\hline Drinking status, n (\%) & $16975(17.81)$ & $9598(18.74)$ & $4648(18.78)$ & $2729(14.10)$ & 199.34 & $<0.001$ \\
\hline Current smoker, n (\%) & $29182(30.62)$ & $16225(31.68)$ & $8071(32.61)$ & $4886(25.25)$ & 293.14 & $<0.001$ \\
\hline Physical activity, n (\%) & $14648(15.37)$ & 7519 (14.68) & $4569(18.46)$ & 2560 (13.23) & 238.61 & $<0.001$ \\
\hline
\end{tabular}

ALT, alanine aminotransferase; BMI, Body Mass Index; DBP, diastolic blood pressure; FBG, fasting blood glucose; hs-CRP, highsensitivity $C$ reactive protein; SBP, systolic blood pressure; TC, total cholesterol; TG, triglyceride; WBC, white blood cell; WC, waist circumference.

with a positive correlation between hs-CRP and agestandardised and sex-standardised incidence of GSD. The incidence of GSD was 5.96 per 1000 person-years, 7.99 per 1000 person-years and 9.13 per 1000 person-years in the $\mathrm{hs}-\mathrm{CRP}<1 \mathrm{mg} / \mathrm{L}, 1 \mathrm{mg} / \mathrm{L} \leq \mathrm{hs}-\mathrm{CRP} \leq 3 \mathrm{mg} / \mathrm{L}$ and hs-CRP $>3 \mathrm{mg} / \mathrm{L}$ groups, respectively. In crude models, elevated hs-CRP concentrations were significantly associated with higher risk of GSD. After adjusting for other aforementioned confounding factors, risk of GSD increased with hs-CRP levels, with the corresponding HR of 1.11 (95\% CI 1.03 to 1.19$)$ and 1.12 (95\% CI 1.04 to 1.22$)$ in the $1 \leq \mathrm{hs}-\mathrm{CRP} \leq 3 \mathrm{mg} / \mathrm{L}$ and hs-CRP $>3 \mathrm{mg} / \mathrm{L}$ groups, respectively.

Table 2 HRs and 95\% Cls of hs-CRP level for risk of newonset gallstone disease

\begin{tabular}{ll}
\hline & Log(hs-CRP) \\
\hline Model 1 & $1.14(1.12$ to 1.17$)$ \\
Model 2 & $1.06(1.04$ to 1.08$)$ \\
Model 3 & $1.03(1.01$ to 1.05$)$ \\
\hline
\end{tabular}

Model 1: univariate analysis.

Model 2: adjusted for age (per 1 year), sex based on model 1. Model 3: further adjusted for total cholesterol (per $1 \mathrm{mmol} / \mathrm{L}$ ), triglyceride (per $1 \mathrm{mmol} / \mathrm{L})$, Body Mass Index (per $1 \mathrm{~kg} / \mathrm{m}^{2}$ ), alanine aminotransferase (per $1 \mathrm{IU} / \mathrm{L})$, current smoker (yes/no), drinking status (yes/no), diabetes (yes/no), hypertension (yes/no) and physical activity (yes/no) based on model 2 .

hs-CRP, high-sensitivity $\mathrm{C}$ reactive protein.
Table 4 shows the effect of hs-CRP on new-onset GSD after stratifying the participants by sex, age or BMI. In multivariate analysis, the effect of hs-CRP on new-onset GSD was not modified by sex. There was a significant positive tendency of elevated risk for GSD as hs-CRP increased in both men and women after adjusting for aforementioned covariates, and the $p$ value for interaction was 0.143 . Similar results were also observed when participants were stratified by BMI, and the $p$ value for interaction was 0.157 . However, when stratified by age, HR values increased only in the youth and middleaged groups and not in the elderly group, and the $p$ value for interaction was $<0.001$.

The AIC and c-statistic for GSD outcomes according to different prediction models were also calculated in this study. The traditional multivariate model contained several risk factors including age, sex, BMI, TC, TG, ALT, smoking status, drinking status, diabetes mellitus, hypertension and physical activity. The improvement of fit and predictive value were analysed after adding hs-CRP to the multivariate model. AIC for the traditional multivariate model and multivariate+hs-CRP model was 88160.76 and 88152.88 respectively. The c-statistics for the traditional multivariate model and multivariate+hs-CRP model were 0.681 and 0.693 , respectively, for GSD, showing a small improvement.

To avoid the effect of acute inflammation, we further excluded participants with hs-CRP greater than $10 \mathrm{mg} / \mathrm{L}$ in the sensitivity analyses. Similar results were also observed where risk of GSD increased with the level of hs-CRP (see online supplemental table S1). 
Table 3 HRs and 95\% Cls for risk of new-onset gallstone disease among participants stratified by high-sensitivity C reactive protein subgroups

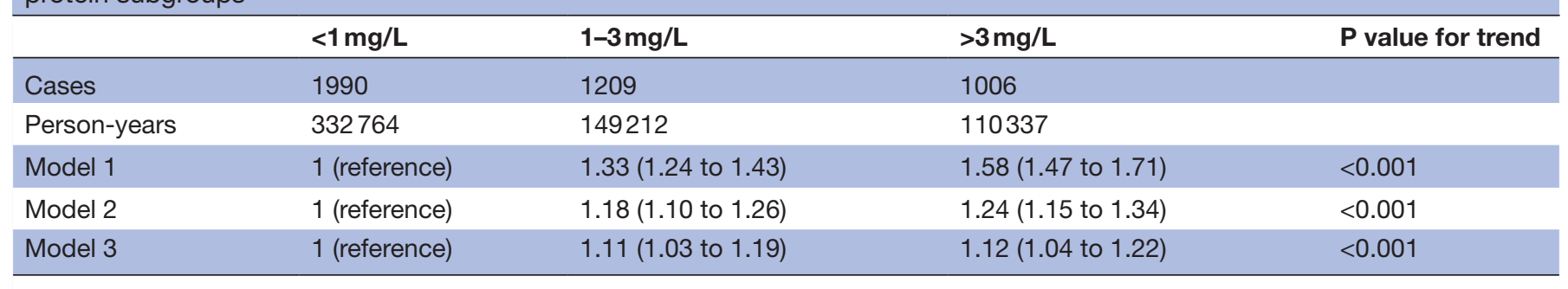

Model 1: univariate analysis.

Model 2: adjusted for age (per 1 year), sex based on model 1.

Model 3: further adjusted for total cholesterol (per $1 \mathrm{mmol} / \mathrm{L})$, triglyceride (per $1 \mathrm{mmol} / \mathrm{L})$, Body Mass $I n d e x\left(\right.$ per $\left.1 \mathrm{~kg} / \mathrm{m}^{2}\right)$, alanine aminotransferase (per $1 \mathrm{IU} / \mathrm{L}$ ), current smoker (yes/no), drinking status (yes/no), diabetes (yes/no), hypertension (yes/no) and physical activity (yes/no) based on model 2.

\section{DISCUSSION}

To our knowledge, this prospective study is the first to analyse the relationship between circulating levels of hs-CRP and the risks of new-onset GSD. The results indicated that elevated hs-CRP concentration was significantly associated with increased risk of GSD in both continuous variable analyses and categorical analyses among 95319 participants.

The overall age-standardised and sex-standardised incidence of GSD was higher compared with other Chinese population-based studies, but still lower than those based

Table 4 HRs (95\% Cls) of gallstone disease stratified analysis by sex, age or BMI

\begin{tabular}{|c|c|c|c|c|c|}
\hline & & $<1 \mathrm{mg} / \mathrm{L}$ & $1-3 \mathrm{mg} / \mathrm{L}$ & $>3 \mathrm{mg} / \mathrm{L}$ & $P$ value for trend \\
\hline \multicolumn{6}{|l|}{ Sex } \\
\hline Men & Cases/person-years & $1562 / 260512$ & 912/115 582 & $724 / 82877$ & \\
\hline \multirow[t]{2}{*}{ Women } & Cases/person-years & $428 / 72251$ & $297 / 33629$ & $282 / 27460$ & \\
\hline & $\mathrm{HR}(95 \% \mathrm{Cl})$ & 1 (reference) & 1.15 (0.98 to 1.33$)$ & 1.26 (1.08 to 1.48$)$ & $<0.001$ \\
\hline \multirow[t]{2}{*}{$\leq 45$} & Cases/person-years & $428 / 125158$ & $197 / 46429$ & $130 / 23739$ & \\
\hline & HR (95\% Cl) & 1 (reference) & 1.15 (0.97 to 1.37$)$ & 1.44 (1.18 to 1.76$)$ & $<0.001$ \\
\hline \multirow[t]{2}{*}{$45 \sim 60$} & Cases/person-years & 1012/159005 & $612 / 72863$ & $468 / 56025$ & \\
\hline & $\mathrm{HR}(95 \% \mathrm{Cl})$ & 1 (reference) & 1.17 (1.06 to 1.30$)$ & 1.25 (1.04 to 1.47$)$ & $<0.001$ \\
\hline$\geq 60$ & Cases/person-years & $550 / 48600$ & $400 / 29920$ & $408 / 30573$ & \\
\hline BMI of $<24 \mathrm{~kg} / \mathrm{m}^{2}$ & $\mathrm{HR}(95 \% \mathrm{Cl})$ & 1 (reference) & 1.07 (0.92 to 1.24$)$ & 1.17 (1.02 to 1.34$)$ & $<0.001$ \\
\hline \multirow[t]{2}{*}{ BMI of $24-28 \mathrm{~kg} / \mathrm{m}^{2}$} & Cases/person-years & $902 / 135727$ & $525 / 67121$ & $468 / 46707$ & \\
\hline & HR (95\% Cl) & 1 (reference) & 1.06 (0.95 to 1.18$)$ & 1.21 (1.08 to 1.36$)$ & $<0.001$ \\
\hline \multirow[t]{2}{*}{$\mathrm{BMI}$ of $>28 \mathrm{~kg} / \mathrm{m}^{2}$} & Cases/person-years & $361 / 47578$ & $396 / 36441$ & $289 / 26636$ & \\
\hline & $\mathrm{HR}(95 \% \mathrm{Cl})$ & 1 (reference) & 1.21 (1.04 to 1.42$)$ & 1.34 (1.16 to 1.55$)$ & $<0.001$ \\
\hline
\end{tabular}

All models were adjusted for age (per 1 year), TC (per $1 \mathrm{mmol} / \mathrm{L}), \mathrm{TG}$ (per $1 \mathrm{mmol} / \mathrm{L}), \mathrm{BMI}$ (per $1 \mathrm{~kg} / \mathrm{m}^{2}$ ), ALT (per $\left.1 \mathrm{IU} / \mathrm{L}\right)$, current smoker (yes/no), drinking status (yes/no), diabetes (yes/no), hypertension (yes/no) and physical activity (yes/no) when participants were stratified by sex.

All models were adjusted for age (per 1 year), sex, TC (per $1 \mathrm{mmol} / \mathrm{L}), \mathrm{TG}$ (per $1 \mathrm{mmol} / \mathrm{L}), \mathrm{BMI}$ (per $\left.1 \mathrm{~kg} / \mathrm{m}^{2}\right)$, ALT (per $\left.1 \mathrm{IU} / \mathrm{L}\right), \mathrm{current}$ smoker (yes/no), drinking status (yes/no), diabetes (yes/no), hypertension (yes/no) and physical activity (yes/no) when participants were stratified by age.

All models were adjusted for age (per 1 year), sex, TC (per $1 \mathrm{mmol} / \mathrm{L}), \mathrm{TG}$ (per $1 \mathrm{mmol} / \mathrm{L}), \mathrm{BMI}$ (per $\left.1 \mathrm{~kg} / \mathrm{m}^{2}\right)$, ALT (per $\left.1 \mathrm{IU} / \mathrm{L}\right), \mathrm{current}$ smoker (yes/no), drinking status (yes/no), diabetes (yes/no), hypertension (yes/no) and physical activity (yes/no) when participants were stratified by BMI.

ALT, alanine aminotransferase; BMI, Body Mass Index; TC, total cholesterol; TG, triglyceride. 
on Western populations. ${ }^{30} 31$ The incidence of GSD varies greatly among different ethnic groups as well as geographical regions. This disparity might be due to the different occurrence of two distinct types of gallstones. Cholesterol stones are common among Western countries, while pigment stones are common in Asia. ${ }^{32}{ }^{33} \mathrm{We}$ speculate that continued increase in the Westernisation of diets and decrease in physical exercise may cause the prevalence and incidence of GSD in the Chinese population to reach the level of its Western counterpart within a short period of time.

Women demonstrated higher incidence compared with men, which was in line with previous research that demonstrated women were almost twice as likely to develop gallstones. ${ }^{34}$ Female predominance in the incidence of GSD could be due to reduced hepatic bile secretion, as female sex hormones increase cholesterol secretion and diminish bile salt secretion. ${ }^{35}$

In this study, we found that an elevated hs-CRP concentration was associated with a higher risk of GSD in univariate analysis. After adjusting for other potential confounding variables, the association between hs-CRP and GSD was attenuated but remained significant. Participants with hs-CRP $>3 \mathrm{mg} / \mathrm{L}$ had $12 \%$ increased risk of GSD versus the lowest hs-CRP level. Similar results were also obtained when participants were stratified by sex or age. However, our study failed to find a positive association of hs-CRP with GSD in elderly people. GSD is rare in neonates and young people, and long-term exposure to risk factors could explain the increased incidence of GSD in the elderly. ${ }^{36}$ In previous studies, older participants were found to have higher hs-CRP concentrations, ${ }^{37}$ and we thus expected to find higher risk of incidence. We currently have no clear explanation for such discrepancy. Further studies should be conducted to investigate whether age eliminates the risk of CRP for GSD among the elderly. Shabanzadeh $e t a l^{38}$ demonstrated that CRP was significantly associated with GSD (OR 1.03, 95\% CI 1.01 to 1.05 ) among 2650 Danish participants which is partially supportive of our findings.

Traditional risk factors such as female gender, ageing, obesity and diabetes mellitus have been demonstrated in previous studies concerning the risk of GSD globally. ${ }^{39} \mathrm{New}$ risk factors should be evaluated in prospective cohort studies to allow for further accuracy in estimation of the actual risk, leading to the most appropriate care and treatment. Our results revealed that the multivariate+hs-CRP model had better fitness and also a better predictive value to help identify new cases of GSD during follow-up. Taking hs-CRP concentration into consideration may be a better method to identify individuals' risk of GSD.

The mechanisms that cause elevation of hs-CRP with increased risk of GSD remain uncertain. Obesity is considered to be closely related to the formation of stones, and previous research suggests that adipose tissues stimulate the secretion of interleukin-6, which is involved in the production of CRP in hepatocytes. ${ }^{37}$ Berk et al found that chronic inflammation of any aetiology might lead to calcium being deposited in the gallbladder wall, which may explain the pathogenesis between CRP and GSD. ${ }^{40}$ In animal experiments, cholesterol crystals were closely associated with inflammation of the gallbladder wall, ${ }^{41}$ as well as increased gallbladder wall thickness. ${ }^{42}$ Elevated gallbladder wall thickness may decrease motility, ${ }^{42}$ suggesting that gallbladder inflammation might cause gallbladder dysmotility. Additional investigations should explore the pathophysiological mechanisms among CRP, cholecystitis and GSD, as well as whether elevated CRP is an indicator of GSD, rather than a sign of acute or chronic cholecystitis.

Ultrasonography has been regarded as the gold standard method for the diagnosis of GSD. The positive predictive value has been reported as $99 \%-100 \%$ and the negative predictive value as $90 \%-96 \% .{ }^{43}$ The availability of ultrasound has facilitated the conduction of epidemiological surveys in Western countries. ${ }^{44}$ Ultrasound examination was also able to represent the true incidence in a defined population as it eliminates the bias of earlier research: necropsy implies death and clinical diagnosis depends on symptoms $(80 \%$ of the stones are clinically silent ${ }^{45}$ ).

The current study is a large-scale population-based study, with a high number of new-onset GSD cases. There were several strengths of this study, including sonography evaluation of the gallbladder, a large sample size and high participation rates during a nearly 8-year follow-up period, and a broad assessment of potential confounders. However, potential limitations should also be noticed. First, we could not distinguish between the two different types of stones (cholesterol and pigment) and the condition of stones by ultrasonographic examination. Second, the incidence was higher in women, but no data concerning the number of pregnancies and the frequency of oral contraceptives were used in our study. Third, there was an imbalance in sex distribution due to the industrial nature of the Kailuan Community. However, the influence of imbalance in sex distribution on the results would be minimal as we carried out independent statistical studies on both genders. Fourth, because of the industrial nature of Kailuan community, a large proportion of participants are labour workers. The results may not be a true representative of the general Chinese population.

The main implications in clinical practice would be an increased awareness of hs-CRP and its correlation to the risk of gallbladder disease. We would like to point out that this is, hopefully, a stepping stone to other insightful research regarding chronic inflammation and gallbladder disease.

\section{CONCLUSION}

Our study confirmed that elevated hs-CRP concentration was an independent risk factor for new-onset GSD among the Chinese population.

Acknowledgements We thank the staff and participants of the Kailuan study for their important contributions.

Contributors TL and STS executed the study and drafted the manuscript. TL, STS and NY participated in the study design and performed the statistical analyses. GX, WL and ND contributed to the discussion. SL and JQ reviewed the manuscript. 
Funding The authors have not declared a specific grant for this research from any funding agency in the public, commercial or not-for-profit sectors.

Competing interests None declared.

Patient and public involvement Patients and/or the public were not involved in the design, conduct, reporting or dissemination plans of this research.

Patient consent for publication Obtained.

Ethics approval This study was approved by the ethics committee of Kailuan General Hospital and was in compliance with the Declaration of Helsinki. Informed consent forms were signed by the participants or their legal representatives.

Provenance and peer review Not commissioned; externally peer reviewed.

Data availability statement No data are available.

Open access This is an open access article distributed in accordance with the Creative Commons Attribution Non Commercial (CC BY-NC 4.0) license, which permits others to distribute, remix, adapt, build upon this work non-commercially, and license their derivative works on different terms, provided the original work is properly cited, appropriate credit is given, any changes made indicated, and the use is non-commercial. See: http://creativecommons.org/licenses/by-nc/4.0/.

ORCID iD

Jun Qu http://orcid.org/0000-0002-9738-2038

\section{REFERENCES}

1 Shaheen NJ, Hansen RA, Morgan DR, et al. The burden of gastrointestinal and liver diseases, 2006. Am J Gastroenterol 2006;101:2128-38.

2 Borch K, Jönsson KA, Zdolsek JM, et al. Prevalence of gallstone disease in a Swedish population sample. relations to occupation, childbirth, health status, life style, medications, and blood lipids. Scand J Gastroenterol 1998;33:1219-25.

3 Moro PL, Checkley W, Gilman RH, et al. Gallstone disease in high-altitude Peruvian rural populations. Am J Gastroenterol 1999;94:153-8.

4 Salinas G, Velásquez C, Saavedra L, et al. Prevalence and risk factors for gallstone disease. Surg Laparosc Endosc Percutan Tech 2004;14:250-3.

5 Everhart JE, Khare M, Hill M, et al. Prevalence and ethnic differences in gallbladder disease in the United States. Gastroenterology 1999;117:632-9.

6 Everhart JE, Ruhl CE. Burden of digestive diseases in the United States Part I: overall and upper gastrointestinal diseases. Gastroenterology 2009;136:376-86.

7 Ruhl CE, Everhart JE. Gallstone disease is associated with increased mortality in the United States. Gastroenterology 2011;140:508-16.

8 Shabanzadeh DM, Sørensen LT, Jørgensen T. Gallstone disease and mortality: a cohort study. Int J Public Health 2017;62:353-60.

9 Shabanzadeh DM, Sørensen LT, Jørgensen T. A prediction rule for risk stratification of incidentally discovered gallstones: results from a large cohort study. Gastroenterology 2016;150:156-67.

10 Attili AF, De Santis A, Capri R, et al. The natural history of gallstones: the GREPCO experience. The GREPCO group. Hepatology 1995;21:656-60.

11 Festi D, Reggiani MLB, Attili AF, et al. Natural history of gallstone disease: expectant management or active treatment? results from a population-based cohort study. J Gastroenterol Hepatol 2010;25:719-24.

12 Shabanzadeh DM. Incidence of gallstone disease and complications. Curr Opin Gastroenterol 2018;34:81-9.

13 Everhart JE, Yeh F, Lee ET, et al. Prevalence of gallbladder disease in American Indian populations: findings from the strong heart study. Hepatology 2002;35:1507-12.

14 Stinton LM, Myers RP, Shaffer EA. Epidemiology of gallstones. Gastroenterol Clin North Am 2010;39:157-69.

15 Katsika D, Grjibovski A, Einarsson C, et al. Genetic and environmental influences on symptomatic gallstone disease: a Swedish study of 43,141 twin pairs. Hepatology 2005;41:1138-43.

16 Ogden CL, Carroll MD, Curtin LR, et al. Prevalence of overweight and obesity in the United States, 1999-2004. JAMA 2006;295:1549-55.

17 Yucel D. C-Reactive protein vs. high - sensitivity C - reactive protein: what is the difference? Turkish Journal of Biochemistry 2014;39:43-4.

18 Higashiyama A, Wakabayashi I, Kubota Y, et al. Does high-sensitivity C-reactive protein or low-density lipoprotein cholesterol show a stronger relationship with the cardio-ankle vascular index in healthy community dwellers?: the Kobe study. J Atheroscler Thromb 2012;19:1027-34.

19 Shafi Dar M, Pandith AA, Sameer AS, et al. hs-CRP: a potential marker for hypertension in Kashmiri population. Indian J Clin Biochem 2010;25:208-12.

20 Marques-Vidal P, Bochud M, Bastardot F, et al. Association between inflammatory and obesity markers in a Swiss population-based sample (CoLaus study). Obes Facts 2012;5:734-44.

21 Zhu Y, Zhang Y, Ling W, et al. Fruit consumption is associated with lower carotid intima-media thickness and C-reactive protein levels in patients with type 2 diabetes mellitus. J Am Diet Assoc 2011;111:1536-42.

22 Michigan A, Johnson TV, Master VA. Review of the relationship between C-reactive protein and exercise. Mol Diagn Ther 2011;15:265-75.

23 Rojo-Martínez G, Soriguer F, Colomo N, et al. Factors determining high-sensitivity $\mathrm{C}$-reactive protein values in the Spanish population. Di@bet.es study. Eur J Clin Invest 2013;43:1-10.

24 Belfki H, Ben Ali S, Bougatef S, et al. Relationship of C-reactive protein with components of the metabolic syndrome in a Tunisian population. Eur J Intern Med 2012;23:e5-9.

$25 \mathrm{Yu}$ J, Dai L, Zhao Q, et al. Association of cumulative exposure to resting heart rate with risk of stroke in general population: the Kailuan cohort study. J Stroke Cerebrovasc Dis 2017;26:2501-9.

$26 \mathrm{Li}$ Z, Wang A, Cai J, et al. Impact of proteinuria and glomerular filtration rate on risk of ischaemic and intracerebral hemorrhagic stroke: a result from the Kailuan study. Eur J Neurol 2015;22:355-60.

27 Wang L, Cui L, Wang Y, et al. Resting heart rate and the risk of developing impaired fasting glucose and diabetes: the Kailuan prospective study. Int J Epidemiol 2015;44:689-99.

28 Liu T, Wang W, Ji Y, et al. Association between different combination of measures for obesity and new-onset gallstone disease. PLoS One 2018:13:e0196457.

29 Pearson TA, Mensah GA, Alexander RW, et al. Markers of inflammation and cardiovascular disease: application to clinical and public health practice: a statement for healthcare professionals from the centers for disease control and prevention and the American heart association. Circulation 2003;107:499-511.

30 Festi D, Barbara L, Frabboni R, et al. Prevalence and incidence of gallstone disease: the Sirmione study[J]. Recent Advances in the Epidemiology and Prevention of Gallstone Disease 1991:7-11.

31 Halldestam I, Kullman E, Borch K. Incidence of and potential risk factors for gallstone disease in a general population sample. $\mathrm{Br} J$ Surg 2009;96:1315-22.

32 Zhu L, Aili A, Zhang C, et al. Prevalence of and risk factors for gallstones in Uighur and Han Chinese. World J Gastroenterol 2014;20:14942-9.

33 Chen J-Y, Hsu C-T, Liu J-H, et al. Clinical predictors of incident gallstone disease in a Chinese population in Taipei, Taiwan. BMC Gastroenterol 2014;14:83.

34 Yamashita N, Yanagisawa J, Nakayama F. Composition of intrahepatic calculi. etiological significance. Dig Dis Sci 1988;33:449e453.

35 Sun $\mathrm{H}$, Tang H, Jiang S, et al. Gender and metabolic differences of gallstone diseases. World J Gastroenterol 2009;15:1886-91.

36 Shaffer EA. Gallstone disease: epidemiology of gallbladder stone disease. Best Pract Res Clin Gastroenterol 2006;20:981-96.

37 Cozma A, Orășan O, Sâmpelean D, et al. Endothelial dysfunction in metabolic syndrome. Rom J Intern Med 2009;47:133-40.

38 Shabanzadeh DM, Skaaby T, Sørensen LT, et al. Metabolic biomarkers and gallstone disease - a population-based study. Scand J Gastroenterol 2017;52:1270-7.

39 Pak M, Lindseth G. Risk factors for cholelithiasis. Gastroenterol Nurs 2016;39:297-309.

40 Berk RN, Armbuster TG, Saltzstein SL. Carcinoma in the porcelain gallbladder. Radiology 1973;106:29-31.

41 Rege RV, Prystowsky JB. Inflammation and a thickened mucus layer in mice with cholesterol gallstones. J Surg Res 1998;74:81-5.

42 van Erpecum KJ, Wang DQ-H, Moschetta A, et al. Gallbladder histopathology during murine gallstone formation: relation to motility and concentrating function. J Lipid Res 2006;47:32-41.

43 Jørgensen T. Prevalence of gallstones in a Danish population. Am J Epidemiol 1987;126:912-21.

44 Jensen $\mathrm{KH}$, Jørgensen T. Incidence of gallstones in a Danish population. Gastroenterology 1991;100:790-4.

45 Sakorafas GH, Milingos D, Peros G. Asymptomatic cholelithiasis: is cholecystectomy really needed? A critical reappraisal 15 years after the introduction of laparoscopic cholecystectomy. Dig Dis Sci 2007;52:1313-25. 